\title{
Research Paper: Basic Psychological Needs in Stuttering and Non-stuttering Iranian Students Aged 13 to 17 Years
}

\author{
Mahdi Akbari' ${ }^{*}$ (D), Mohammad Ali Safaee Navaee² (D) \\ 1. Department of Psychology, Faculty of Humanities and Social Sciences, University of Mazandaran, Babolsar, Iran. \\ 2. Department of Rehabilitation, Rehabilitation Office, Amol, Iran.
}

\begin{tabular}{|l|l|}
$\begin{array}{c}\text { Use your device to scan } \\
\text { and read the article online }\end{array}$ \\
Cittation: Akbari M, Safaee Navaee MA. Basic Psychological Needs in Stuttering and Non-stuttering Iranian Students Aged \\
13 to 17 Years. Journal of Modern Rehabilitation. 2018; 12(4):253-258. http://dx.doi.org/10.32598/JMR.V12.N4.253
\end{tabular}

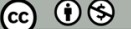

Article info:

Received: 25 May 2018

Accepted: 22 Aug 2018

Available Online: 01 Oct 2018

\section{Keywords:}

Adult satisfaction, Psychological needs, Students aged 13-17 years, Stuttering disorder

\section{ABSTRACT}

Introduction: This study seeks to answer the question: "What is the difference between the basic psychological needs (survival, love and belonging, power, freedom, and fun) of stuttering and non-stuttering students?"

Materials and Methods: The present study was conducted on 15 stuttering students aged 13 to 17 years as the case group and 15 non-stuttering students (13 males and two females) aged 13 to 17 years as the control group. The formal validity, reliability, and internal consistency of the questionnaire were assessed.

Results: Analysis showed significant differences between the two groups in need of love and belonging, and fun $(\mathrm{P}<0.001)$ and stuttering students showed more desire for love, belonging, and fun. Furthermore; analysis indicated insignificant differences between two groups in survival, power, and freedom needs $(\mathrm{P}<0.001)$.

Conclusion: Stuttering students are more in need of love and belonging; that is, the need for relationships, social connections, giving and receiving affection, and feeling to be a part of a group. They, moreover, need more to find pleasure, to play, and to laugh.

\section{Introduction}

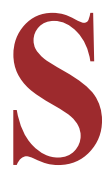

tuttering is a systemic problem. It involves the speech, thoughts, and feelings of the speaker, but it may also affect communication with partners, other respondents, unknowing and knowing audiences, and bystanders $[1,2]$. According to Shapiro, stuttering is defined as the "individualized and involuntary interruptions in the forward flow of speech and learned reactions thereto interacting with and generating associated thoughts and feel- ings about one's speech, oneself as a communicator and the communicative world, in which one lives" [3]. In adults, it is a social communication disturbance, which is chronic.

One of its major components is the individual's response to the "loss of control" during the stuttering event. As such, individuals who stutter often require assistance on fluency-increasing strategies and techniques, as well as attitudes and feelings about living with a chronic communication disability $[4,5]$. For students who stutter, the transition from childhood to adolescence may place them

* Corresponding Author:

Mahdi Akbari, PhD.

Address: Department of Psychology, Faculty of Humanities and Social Sciences, University of Mazandaran, Babolsar, Iran.

Tel: +98 (911) 2216351

E-mail: mahdiakbari1362@gmail.com 
at a higher risk for the development of anxiety issues and psychological distress as a result of the psychosocial effects of the disorder [6-10]. They may also be at high risk for psychological stress during this time because of the likelihood of "recovering" from developmental stuttering decreases. During adolescence, the awareness of stuttering converting to a chronic disability becomes a reality for one of every five children, who exhibit stuttering behaviors [11]. Stuttering can be identified as both a speech event and a disorder [12].

As a speech event, stuttering is an involuntary disruption of the smooth execution of a speaker's intentional speech act $[4,12]$. As adolescents begin to feel greater pressure to communicate effectively in social situations, they may choose to avoid communication altogether, hide their stuttering with the word or phrase substitutions, and attempt to find functional solutions for their social communication disorder or establish secure social support networks [13].

The reasons for stuttering have not been clear at all. But, stuttering cannot have a single cause. It is always caused by the physical, emotional, social, or a combination of these factors. Many people with stuttering problem experience some psychological discomfort and social incompatibilities. In some cases, stuttering may be the result of nerve defects and disorders or some mild physiological abnormalities [14].

For over 50 years, Glasser was developing choice theory. The basis of his argument is the beliefs of internal and external control psychology. In the psychology of internal control, "humans have the ability and power to choose in relation to their individual and professional behavior". In the psychology of external control, "humans have the ability to communicate with others and play their roles in their relationship" [15].

Glasser began his work with the harsh criticism, stating that current treatments for mental health had not been effective, and for this reason, he created a reality therapy. Then, in 1998, he established the choice theory [16]. He stressed that the motive of all human behavior came from five essential needs, which are innate, universal, and consistent.

In the choice theory, it is believed that we are eager to satisfy our needs by establishing our own "qualitative world". The world of quality includes our interests, beliefs, and desires. In any case, when there is a perceived difference between what we have achieved and what we want, we try to minimize or eliminate the failure as we approach our needs and fulfill our desires [14]. Accordingly, a relationship between the lack of satisfying basic psychological needs and behaviors in students can be predicted. Glasser's description of the behavior is more humanistic than behavioral and uses five basic needs to describe how we behave. His choice theory divides basic human needs into five parameters of power, survival, love and belonging, freedom, and fun.

The need for survival is a physiological need, which includes the need for food, shelter, and safety. Because we have genetic instructions to survive, not only as individuals but also as a species, this includes the need to reproduce. The sense of belonging consists of the need for love and affection, showing feelings and emotions to others, seeking intimacy, time and energy for the family communication, creating and maintaining friendships, as well as membership in a group. Power and self-actualization include the needs for reaching the target, achievement, sense of control over the circumstances, having skills, having self-confidence, sense of honor, influencing others, a sense of competition, following a pattern and being followed.

To be powerful is to achieve, to be competent, to be skilled, to be recognized for our achievements and skills, to be listened to, and to have a sense of self-worth. Freedom includes the need not to be limited and forced, the need to feel the freedom of action and decision-making, travel, independence of judgment and action, having plenty of choices, autonomy, creativity, and expression without fear. The need to be free is the need for independence, autonomy, to have choices, and to be able to take control of the direction of one's life. The fun includes the need for laughing, learning, seeking variety, engaging in favorite hobbies, having fun, playing, and sense of humor and joy. The need for fun is the need to find pleasure, to play, and to laugh. If you doubt that this is as important as any of the others, imagine a life without hope of any enjoyment. Glasser links the need for fun to learning. All of the higher animals (dogs, dolphins, primates, etc.) play. As they play, they learn essential life skills. Human beings are not different. It is true that "play is a child's work" $[14,17]$.

This study aims to investigate the difference between the fundamental psychological needs among stuttering and non-stuttering students in Amol City, Iran. This study seeks to answer the question: "What is the difference between the basic psychological needs of stuttering and non-stuttering students?"

\section{Materials and Methods}

\section{Study participants}

A sampling method was used to select 30 students aged 13 to 17 years. They were divided into experiment and control 
groups. A total of 15 students with the stuttering disorder (13 males and two females) were in the experiment group, and 15 students without stuttering disorders (13 males and two females) were in the control group. For each student, a standard questionnaire was implemented. The inclusion criteria for the stuttering group consisted of the age range of 13 to 17 years, the lack of psychological or neurological defects, reading and writing education, and stuttering. Also, the inclusion criteria for the control group consisted of age, gender, and education matching the stuttering group, and the lack of stuttering.

All participants received explanations on how to do the test, and they were given enough time to complete the questionnaire. After completing the questionnaire, the necessary information related to each subject, such as age, sex, and education, was also gathered. Speech-Language Pathologists (SLPs) were contacted regarding potential participants. SLPs communicated with potential participants and their parents, who directly contacted the authors. After an explanation of the study and invitation to participate, the appointments were scheduled. The diagnosis of stuttering was confirmed, using: A.standardized procedures to evaluate stuttering behaviors, including part-word repetitions, tense pauses, and prolongations; B. the participants' history of stuttering (i.e. onset, duration, familial report, and developmental data.); C. 200-word monologues, reading samples, and conversational speech samples; and D. the severity of stuttering ratings using the stuttering severity instrument and scales measuring attitudes and feelings toward stuttering.

\section{Study instruments}

Glasser's Questionnaire of Basic Psychological Needs

William Glasser introduced basic psychological needs and highlighted five basic human needs, which are internal, universal, dynamic, and consistent with each other. Some researchers designed a questionnaire based on Glasser's theory, comprising of 35 items, in which the intensity of each component (needs) was measured by a seven-point Likert scale [17]. The reliability coefficient obtained through Cronbach alpha in the present study was 0.77 for basic psychological needs, and they were $0.78,0.78,0.78$, 0.77 , and 0.78 for the need for survival, love and belonging, freedom, self-worth and empowerment, and fun and enjoyment, respectively, indicating an acceptable level of reliability. To evaluate the scale validity, the correlation of each question with the total score was calculated.

\section{Stuttering Diagnostic Inventory}

This inventory was used to assess the stuttering disorder. Its validity was confirmed in previous studies, and the reliability was obtained through Cronbach alpha (0.78).

\section{Data analyses}

Information obtained through questionnaires was analyzed, using SPSS V. 22. The research hypotheses were tested, using the t-test at the significance level of 0.01 . The data of the participants were compared in stuttering and non-stuttering students.

This statistical test shows that the performance differences between the two groups are statistically significant. If the result of this test is less than 0.01 , the difference will be significant. If the result of this test is not less than 0.01 , the performance of the two groups will not be statistically significant.

\section{Results}

Table 1 presents the results of the analysis through the student's t-test. The results of the analysis of t-test revealed significant differences in love and belonging and fun needs $(\mathrm{P}<0.001)$. The results indicated that compared to non-stuttering students, stuttering students more needed love, belonging, and fun. But, the analysis showed insignificant differences in survival, power, and freedom needs $(\mathrm{P}<0.001)$.

\section{Discussion}

It is possible to assume that stuttering is a psychological and social phenomenon. Stuttering students also fear and avoid social situations because they consider themselves vulnerable to negative evaluations of others. When people are in a social position, they assume that others are negatively monitoring and evaluating their appearance, behavior, and function. The analysis showed that differences in survival, power, and freedom needs between stuttering and non-stuttering students are not significant. Survival includes human health needs, the continuation of life and reproduction, the needs for security, and academic success. Power, prestige, respect, recognition by others, taking enjoyment from competitions, the fear of vulnerability, making efforts, and fame because of endeavors and achievements are among the needs associated with self-worth and empowerment.

Freedom refers to the control of one's lifestyle, the selection of desired options, freedom of speech, cooperation with favorite people, the continuation of desired occupa- 
Table 1. Studying the difference in psychological needs between stuttering and non-stuttering students

\begin{tabular}{|c|c|c|c|c|}
\hline Needs & Group & Mean $\pm S D$ & $\mathbf{t}$ & Sig. \\
\hline Survival & $\begin{array}{c}\text { Stuttering } \\
\text { Non-stuttering }\end{array}$ & $\begin{array}{l}4.35 \pm 0.36 \\
4.42 \pm 0.31\end{array}$ & 1.74 & 0.36 \\
\hline Love \& belonging & $\begin{array}{c}\text { Stuttering } \\
\text { Non-stuttering }\end{array}$ & $\begin{array}{l}3.45 \pm 0.32 \\
4.21 \pm 0.22\end{array}$ & 4.79 & $0.001 *$ \\
\hline Power & $\begin{array}{c}\text { Stuttering } \\
\text { Non-stuttering }\end{array}$ & $\begin{array}{l}4.24 \pm 0.30 \\
4.31 \pm 0.28\end{array}$ & 1.85 & 0.22 \\
\hline Freedom & $\begin{array}{c}\text { Stuttering } \\
\text { Non-stuttering }\end{array}$ & $\begin{array}{l}4.17 \pm 0.33 \\
4.26 \pm 0.34\end{array}$ & 1.63 & 0.41 \\
\hline Fun & $\begin{array}{c}\text { Stuttering } \\
\text { Non-stuttering }\end{array}$ & $\begin{array}{l}4.18 \pm 0.24 \\
4.74 \pm 0.29\end{array}$ & 3.45 & $0.001^{*}$ \\
\hline
\end{tabular}

$* \mathrm{P}=0.01$

tion or activity, and being free from physical or psychological discomforts such as fear, stress, disrespect, and monotony [18]. As noted in the results section, stuttering students feel that they need more belonging and love in themselves, showing that they have problems with useful emotions in their social relations.

Stuttering students need a lot of love, affection, and affinity. There is a less fundamental psychological need for students without stuttering. One of the most important explanations for this finding can be the embarrassment of stuttering students, which reduces their self-esteem to the extent that shyness and diffidence result in their need for relationship. The usual reaction is that the person feels he or she is not good enough when his or her conduct/performance is compared to the social norms and standards.

Stuttering students are more in need of love and belonging in their relationships and social interactions, giving and receiving affection, and feeling to be a part of a group. Fun and enjoyment covers the need for pleasure, joy, laughing, playing, and having leisure time [14]. This result is supported by some studies [19-21]. It is often necessary to pay considerable attention to advanced stutterers' negative feeling and attitudes in therapy $[22,23]$. So, besides the classic speech therapy procedures, additional psychological-based treatment and counseling should address problems possibly linked to the stuttering (e.g. social fears) [20,21]. Here, the speech therapist could also examine the patient's feelings, beliefs, and experiences, along with a focus on the treatment of the speech symptoms [24]. The results of this research, which examined the personality dimensions of stutterers suggested that stuttering people, compared to the normal ones, showed higher levels of personality psychological needs and lower levels of externality [25].

The results of this study also indicated that stuttering students, who sought treatment for their stutter, showed higher levels of psychological needs compared to the control group (Table 1). Embarrassment is a kind of internal alarm that helps the person to find out when he is at risk of falling outside the scope of admission and social satisfaction. A person who is shy and afraid of being embarrassed is concerned about being at the center of attention of others. These people generally avoid public speaking, chatting with others, being motivated or in situations, where a large number of people gather together. Unfortunately, the same reaction increases the severity of this problem.

People who suffer from this problem always try to cover their faces unnecessarily, ignoring the fact that this action intensifies their problems. Fear of redness of the face can occur with other symptoms such as shortness of breath, dizziness, excessive sweating, chills, nausea, dry mouth, feeling sick, palpitations, inability to speak or think, fear of dying, fear of loss giving control, feeling unreliable, or attacking anxiety [26]. Also, the results showed that stuttering students need more to find pleasure, to play, and to laugh Need of love and belonging comprised individual's love and intimacy, attention to one's health status and that of other individuals, seeking acquaintance with other people, having close relationships with friends, feeling comfortable 
with family, and having satisfying relationships with oneself and others. The results of this study are consistent with the findings of other studies $[27,28]$.

Anxiety, depression, and fear of negative evaluation experienced by individuals who stutter are secondary to stuttering and the result of having to cope with a serious communication problem [28-30]. As Guitar states, “...the experience of stuttering generates emotions, such as frustration, fear, and anger in everyone who stutters" [22]. This perspective is noted within the Diagnostic and Statistical Manual of Mental Disorders, as stuttering is mentioned as a condition, which may cause excessive social anxiety, but it is conceptualized as a reaction to this medical condition. It is worth mentioning that the observed differences in fundamental psychological needs between stutterers and nonstutterers do not necessarily imply special psychological needs or specific personality patterns in stuttering students. There may be significant differences between stuttering and non-stuttering students with psychological and emotional social impacts of communication difficulties and adverse outcomes associated with stuttering throughout life. These differences arise when these individuals experience the negative stereotypical behaviors, worries, and social abandonment, as well as adverse reactions of the audience, fear of talking in the crowd, anxiety, and social fears [26, 31].

The results of the present study revealed that mean scores of the needs were significantly higher in students who stutter compared to the control group. Students who stutter need substantially more love and belonging, as well as fun compared with students in the control group. The results of this study were also supported by the findings of other studies [21, 32].

In summary, the findings of the study emphasized the importance of psychotherapies along with speech therapies for treating the problems of students with stuttering in establishing emotional and social relationships with others, having a sense of happiness, and in general, having positive experiences both during pre-treatment evaluation and planning for it and in the process of treatment. One of the main and most prevalent causes of depression, anxiety, and obsession that the authors have observed in the patients during the present study is the lack of a sense of happiness and enjoyment of social relationships. Stuttering is a lasting disorder that affects occupational, social, and educational development, as well as the achievements of people with stuttering. It is suggested that combined interventions be carried out with the help of speech therapists and psychologists to treat stuttering in students. It is also recommended that psychotherapy techniques be taught to speech thera- pists so that they can use these interventions in treating stuttering.

\section{Ethical Considerations}

\section{Compliance with ethical guidelines}

All ethical principles were considered in this article. The participants were informed about the purpose of the research and its implementation stages. They were also assured about the confidentiality of their information; Moreover, They were allowed to leave the study whenever they wish, and if desired, the results of the Research would be available to them.

\section{Funding}

This research did not receive any specific grant from funding agencies in the public, commercial, or non-profit sectors.

\section{Authors contributions}

All authors contributed equally in preparing this article.

\section{Conflict of interest}

The authors declared no conflict of interest.

\section{Acknowledgements}

The authors highly appreciate the support of the students at the $7^{\text {th }}$ to $11^{\text {th }}$ grades at Amol schools.

\section{References}

[1] Guitar B. Stuttering: An integrated approach to its nature and treatment. Philadelphia: Lippincott Williams \& Wilkins; 2013.

[2] Manning WH, DiLollo A. Clinical decision making in fluency disorders. New York: Plural Publishing; 2017.

[3] Shapiro DA. Stuttering intervention: A collaborative journey to fluency freedom, Austin: PRO-ED Inc; 1999

[4] Shapiro DA. Stuttering intervention: A collaborative journey to fluency freedom. (2nd Ed), Pro-Ed: Austin Texas. PRO-ED Inc; 2011.

[5] Yairi E H, Seery CH. Stuttering: Foundations and clinical applications. London: Pearson; 2014

[6] Blood GW, Blood IM. Preliminary study of self-reported experience of physical aggression and bullying of boys who stutter: Relation to increased anxiety. Perceptual and Motor Skills. 
2007; 104(suppl. 3):1060-6. [DOI:10.2466/pms.104.3c.1060-1066] [PMID]

[7] Blood GW, Blood IM, Maloney K, Meyer C, Qualls CD. Anxiety levels in adolescents who stutter. Journal of Communication Disorder. 2007; 40(6):452-69. [DOI:10.1016/j.jcomdis.2006.10.005] [PMID]

[8] Blood GW, Blood IM, Tellis GM, Gabel RM. A preliminary study of self-esteem, stigma, and disclosure in adolescents who stutter Journal of Fluency Disorders. 2003; 28(2):143-58. [DOI:10.1016/ S0094-730X(03)00010-X]

[9] Gunn A, Menzies RG, O'Brian S, Onslow M, Packman A, Lowe $\mathrm{R}$, et al. Axis I anxiety and mental health disorders among stuttering adolescents. Journal of Fluency Disorders. 2014; 40:58-68. [DOI:10.1016/j.jfludis.2013.09.002] [PMID]

[10] Smith KA, Iverach L, O'Brian S, Kefalianos E, Reilly S. Anxiety of children and adolescents who stutter: A review. Journal of Fluency Disorders. 2014; 40:22-34. [DOI:10.1016/j. jfludis.2014.01.003] [PMID]

[11] Howell P. Recovery from stuttering. Abingdon: Psychology Press; 2011. [DOI:10.4324/9780203847404]

[12] Yairi E, Seery CH. Stuttering: Foundations and clinical applications. Upper Saddle River: Pearson; 2015.

[13] Blood GW, Blood IM, Dorward S, Boyle MP, Tramontana GM. Coping strategies and adolescents: Learning to take care of self and stuttering during treatment. Perspectives on Fluency and Fluency Disorders. 2011; 21(3):68-77. [DOI:10.1044/ffd21.3.68]

[14] Fay N, Page AC, Serfaty C, Tai V, Winkler C. Speaker overestimation of communication effectiveness and fear of negative evaluation: Being realistic is unrealistic. Psychonomic Bulletin \& Review. 2008; 15(6):1160-5. [DOI:10.3758/PBR.15.6.1160] [PMID]

[15] Glasser W. Choice theory: A new psychology of personal freedom. New York: HarperCollins; 2016.

[16] Glasser W. Warning: Psychiatry can be hazardous to your mental health. New York: HarperCollins Publishers; 2003

[17] Burns MK, Vance D, Szadokierski I, Stockwell C. Student needs survey: A psychometrically sound measure of the five basic needs. International Journal of Reality Therapy. 2006; 25(2):4-8.

[18] Glasser W. Take charge of your life: How to get what you need with choice-theory psychology. Indiana: iUniverse; 2013.

[19] Blomgren M, Roy N, Callister T, Merrill RM. Intensive stuttering modification therapy. Journal of Speech, Language, and Hearing Research. 2005; 48(3):509-23. [DOI:10.1044/10924388(2005/035)]

[20] Guitar B, McCauley RJ. Treatment of stuttering: Established and emerging interventions. Philadelphia: Lippincott Williams \& Wilkins; 2010

[21] Bleek B, Montag C, Faber J, Reuter M. The five factor model of personality applied to persons who stutter and a matched control group. Journal of Communication Disorders. 2011; 44:218-22. [DOI:10.1016/j.jcomdis.2010.11.001] [PMID]

[22] Guitar B. Stuttering: An integrated approach to its nature and treatment. Philadelphia: Lippincott Williams \& Wilkins; 2006.
[23] Beilby, J. Psychosocial impact of living with a stuttering disorder: Knowing is not enough. Seminars in Speech and Language. 2014; 35(2):132-43. [DOI:10.1055/s-0034-1371756] [PMID]

[24] Jafari R, Shahbodaghi R, Ashayeri H, Keyhani M, Baziyar M. The five factor model of personality and stuttering. ProcediaSocial and Behavioral Sciences. 2014; 127:307-10. [DOI:10.1016/j. sbspro.2014.03.261]

[25] Bleek B, Montag C, Faber J, Reuter M. Investigating personality in stuttering: Results of a case control study using the NEOFFI. Journal of Communication Disorders. 2011; 44(2):218-22. [DOI:10.1016/j.jcomdis.2010.11.001] [PMID]

[26] Pellowski MW, Conture EG. Characteristics of speech disfluency and stuttering behaviors in 3-and 4-year-old children. Journal of Speech, Language, and Hearing Research. 2002; 45(1):2035. [DOI:10.1044/1092-4388(2002/002)]

[27] Arslan A. Basic needs as a predictors of prospective teachers' self-actualization. Universal Journal of Educational Research. 2017; 5(6):1045-50. [DOI:10.13189/ujer.2017.050618]

[28] Cummings EM, Greene AL, Karraker KH. Life-span developmental psychology: Perspectives on stress and coping. Abingdon-on-Thames: Psychology Press; 2014. [DOI:10.4324/9781315807867]

[29] Craig A, Tran Y. Trait and social anxiety in adults with chronic stuttering: Conclusions following meta-analysis. Journal of Fluency Disorders. 2014; 40:35-43. [DOI:10.1016/j. jfludis.2014.01.001] [PMID]

[30] Blumgart E, Tran Y, Craig A. Social anxiety disorder in adults who stutter. Depression and Anxiety. 2010; 27(7):687-92. [DOI:10.1002/da.20657] [PMID]

[31] Plexico L, Manning WH, DiLollo A. A phenomenological understanding of successful stuttering management. Journal of Fluency Disorders. 2005; 30(1):1-22. [DOI:10.1016/j. jfludis.2004.12.001] [PMID]

[32] Bleek B, Reuter M, Yaruss JS, Cook S, Faber J, Montag C. Relationships between personality characteristics of people who stutter and the impact of stuttering on everyday life. Journal of Fluency Disorders. 2012; 37(4):325-33. [DOI:10.1016/j. jfludis.2012.07.003] [PMID] 